\title{
A Continuous Improvement and Monitoring Performance System: Monitor - Analysis - Action - Review (MAAR) Charts
}

\author{
Vito Romaniello ${ }^{1}$, Paolo Renna ${ }^{2}$ and Vincenzo Cinque ${ }^{1}$ \\ ${ }^{1}$ ANSALDO STS, Tito Scalo (PZ), Italy \\ ${ }^{2}$ University of Basilicata - DIFA, Potenza, Italy
}

\begin{abstract}
The research presented in this paper concerns the development of a methodology for monitoring and continuous performance improvement. The proposed approach is derived from the classical Deming cycle adapted to a real industrial environment. The approach consists of four phases: Monitor, Analysis, Action and Review (MAAR); these phases are summarized in a single information panel that allows to improve the monitoring process. This paper presents a discussion of the real case study application of the methodology in area manufacturing of ANSALDO STS S.p.A. The case study discussed here shows the application of basic principles, management tools and techniques towards performance improvement in a manufacturing plant. The innovative issues of the MAAR approach developed regard: the possibility to apply the methodology to wide fields of enterprises (as maintenance, quality management, design, financial, etc.) and the real-manufacturing orientation. The results show the real benefits obtained by the implementation of the proposed methodology.
\end{abstract}

Keywords: quality management, continuous improvement, manufacturing systems, industrial case study, performance monitoring.

\section{Introduction}

The measure of performance is a question in which all companies are involved. The performance monitoring has the goal to improve the ability for the control process of the results of a company. There must be clear objectives, indicators, operational plans, and then we measure the performance achieved. Often, the common meaning of performance is confused with the efficiency of direct labor, which tends to take marginal importance compared with the other inputs, such as nonquality costs, productivity, material, indirect labor and capital invested in stocks and assets.

A monitoring system is necessary to measure the achievement of targets, and the deviation from the objectives; The instrument will be more effective and accurate if it can track the individual contributors that affect directly and indirectly objectives. The difficulties of setting up a system of performance measurement are not few. For example, an initial problem is to determine the period of controlling and planning. If the time periods are too long, the connection between goals

Copyright (C2011 Vito Romaniello, Paolo Renna and Vincenzo Cinque. This is an open access article distributed under the Creative Commons Attribution License unported 3.0, which permits unrestricted use, distribution, and reproduction in any medium, provided that original work is properly cited. Contact author: Vito Romaniello e-mail: vito.romaniello@ansaldo-sts.com 
and daily actions may be lost. If the time periods are too short, the necessary freedom of action may be lost.

The main characteristics of the system to pursue what planned are the following: a dynamic and flexible system; to be able to monitor in real-time the performance; to detect the contributors which adversely affect performance; to show the trend of the individual contributors; furthermore, based on these elements, the system has the possibility to trigger a system of continuous improvement.

The MAAR chart methodology was born as an operational need to respond in real time to the trends of the Key Performance Indicators (KPIs) and it needs to be able to take decisions on possible corrective actions more quickly than KPIs.

The embryo of this methodology was implemented and tested in production environments of electronic cards of Ansaldo STS Company in the factory of Tito (PZ, Italy) and it allowed to monitor and improve the already high quality performance products. This methodology allowed finding the right tool to monitor and keep the high levels of performance on product quality.

The paper is structured as follows. Section 2 provides a briefly review of the literature on the methodologies developed for continuous improvement. The proposed methodology is described in Section 3, while in Section 4 the case study is discussed. Finally, in Section 5 the conclusions and future development are discussed.

\section{Literature Review}

Many authors investigated the productivity measurement and improvement problem in manufacturing systems. Muthiah and Huang (2006) presented a literature review on manufacturing systems productivity measurement and improvement. They classified the literature under four categories: operations research based methods, system analysis-based methods, continuous improvement methods and performance metrics-based methods. Moreover, they presented a survey of the methodologies proposed in literature as showed in table 1 .

Table 1: Methodologies Proposed in Literature

\begin{tabular}{|c|c|}
\hline Methodologies proposed & Main scientific literature references \\
\hline $\begin{array}{c}\text { Graphs with Results and Actions } \\
\text { Interrelated (GRAI) }\end{array}$ & $\begin{array}{c}\text { Doumeingts (1985); Doumeingts et al. (1995); } \\
\text { Grislain and Pun (1979) }\end{array}$ \\
\hline $\begin{array}{c}\text { Integrated Compute-Aided Manufacturing } \\
\text { Definition (IDEF0) }\end{array}$ & $\begin{array}{c}\text { Bravoco and Yadav (1985); Ross (1985) } \\
\text { (SADT) }\end{array}$ \\
\hline $\begin{array}{c}\text { Structured Analysis and Design Technique } \\
\text { Marca and McGowan (1988); Ross and } \\
\text { Schoman }\end{array}$ \\
$\begin{array}{c}\text { (1977); Ross (1985); Santarek and Buseif } \\
\text { (1998) }\end{array}$ \\
\hline $\begin{array}{c}\text { Structured Systems Analysis and Design } \\
\text { Method (SSADM) Structured Systems }\end{array}$ & Down et al. (1988); Eva (1992) \\
\hline GRAI Integrated Methodology (GIM) & Doumeingts et al. (1995) \\
\hline $\begin{array}{c}\text { Strathclyde Integration Method (SIM) } \\
\text { (1997) }\end{array}$ & Carrie and Macintosh (1997); Pandya et al. \\
\hline GI-SIM (GRAI grid, IDEF0 and SIMAN tools) & Al-Ahmari and Ridgway (1999) \\
\hline
\end{tabular}


However, these modeling techniques are not designed to facilitate productivity measurement and analysis. Rather they focus on the availability of the unit/equipment, which is only one aspect of the system performance (Huang et al., 2002).
Taninecz (2004a) reports a summary of IW/MPI Census plants' progress towards achieving world-class manufacturing status from enterprises across USA. From this report, more than $75 \%$ of plants have no progress or some progress. Figure 1 shows the methodologies and percentage of plants with improvements (Taninecz, 2004b).

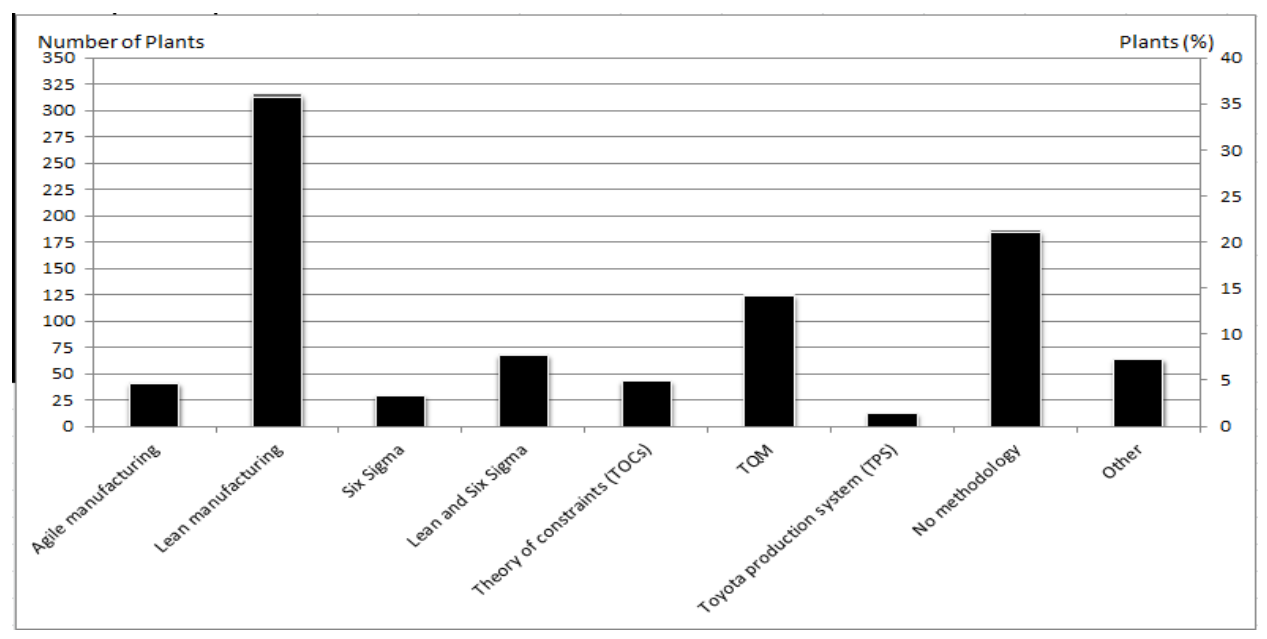

Fig 1. Methodologies and Improvements

Figure 1 shows the methodologies that are more used. The survey (Taninecz, 2004b) described that the plants with no methodology have poor manufacturing performance; therefore any methodology is better than no methodology implementation. The survey concludes that a methodology will only be good according to those who guide and execute it.

Witcher and Chau (2007) discussed a complementary use of the balanced scorecard and hoshin kanri. It aims to posit a model for the combination of these long and short-term organizational activities as a framework for a senior level to manage a firm strategy that fits as an integrated organization-wide system that links top management goals to daily management.

Friday-Stroud and Sutterfield (2007) proposed a framework to integrate six-sigma and strategic management methodologies to quantify decision making. Also, this paper concerns the strategic decision in mediumlong term.

Witcher and Chau (2008) presented two contrasting applications of the balanced scorecard, at EDF Energy and Tesco, where the scorecard is called a steering wheel. A distinction is drawn between a strategic scorecard based on vision and a performance management scorecard based on mission and values. Execution is the translation of midterm plans into annual priorities for daily or routine work.

Wazed and Ahmed (2009) presented a case study on how a theory driven real time empirical investigation can offset the quality related problems and bring better results in other performance dimensions. A systematic approach and application of the basic and advanced management tools and techniques are used to solve the rejection part problem 
in a plastic moulding manufacturing plant. In order to illustrate this, the study focused on From the discussion of the recent literature (reported above) the following issues can be drawn:

- Most of the studies focused only on one part: the framework to manage the improvements or the performance analysis in order to make a decision.

- The approaches proposed in literature focus on particular enterprise's area such as: maintenance, product development, quality control, etc; or they focus on particular typology of enterprise.

The research presented in this paper overcomes the above limits by a general and integrated approach called Monitor Analysis Action Review (MAAR). The approach proposed is characterized by a module for introducing analysis and collecting the performance information in order to provide the important issues to take the improvement decision. The second module manages the improvement actions from a managerial point of view in order to check the status of the actions and their success.

\section{MAAR Chart Methodology}

The methodology proposed is a practical application tool based on Deming cycle (PlanDo-Act-Check). The MARR chart tool proposes a dashboard that allows supervising, introducing corrective actions and tracking the status/efficacy of them. All these information are showed in a compact style in order to facilitate the use in real applications and highlight the problems in the first stage of corrective actions introduction. joint application of PDCA and 5S approaches.

The second important issue concerns the time horizon; the proposed methodology is adaptable for both short-term and mediumterm, therefore, it can be applicable to several levels of an enterprise.

The third issue is the modularity of the tool proposed; this characteristic allows the adaption of the tool to several different industrial processes to improve.

If the methodology is implemented, then using a computerized system can monitor in real time key performance Indicators (KPIs), highlight in real time the causes of possible factors affecting KPIs negatively and the trend of these factors in previous periods; then it can implement corrective actions outlined in the system.

The use of computer allows taking data directly from the machines with the possibility of data entry with bar code technology or RFID, etc.

Using multiple joint technology from the possibility of taking data at no cost and process in real time, and only if this data has a negative impact on KPIs, will implement actions for continuous improvement.

The objectives pursued by the MAAR tool are two: the continuous improvement and the analysis of resources use. The tool proposed applies the four phases of Deming Cycle with the continuous interaction of all the actors involved in the generic process supervised.

Figure 2 shows the Deming cycle thinking applied to the proposed methodology. 
5 IBIMA Business Review

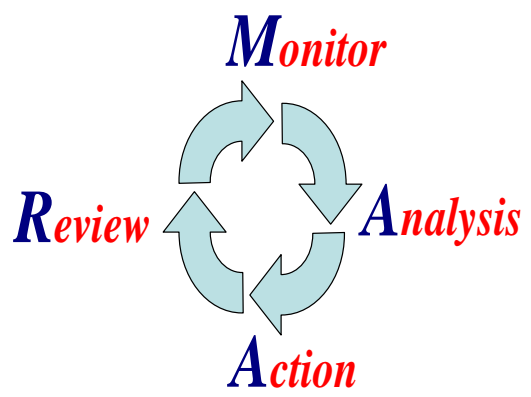

Fig 2. Continuous Improvement Cycle

The steps shown in figure 2 are the following:

- Monitor; the dashboard developed allows showing the significant information in a compact mode.

- Analysis; the human analyst analyzes the information in order to propose corrective actions.

- Action; the actions have to be introduced in the tool with responsible and available resources.
- Review; in this step the effects of the corrective actions are evaluated.

The first activity to perform is to define numerical objectives for each step: Key Performance Indicator (KPI). KPIs have to be determined for the specific industrial process in which the tool is introduced. In the following, each step will be described in details. The view of the dashboard is very compact and an example of the KPI monitoring is showed in figure 3.

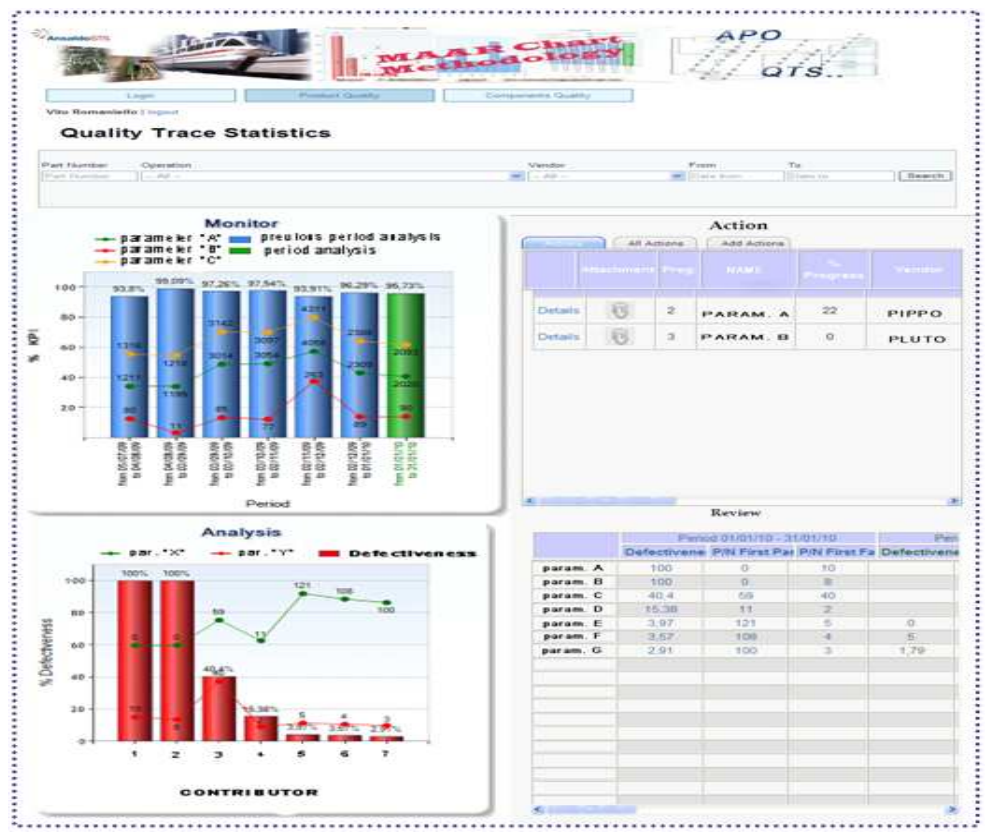

Fig 3. Typical Mask for a KPI Monitoring Trough MAAR Chart Methodology 
Before starting with the methodology, it is important to set the KPIs relevant to the control at various stages of the process, service or other activities. Everyone (involved in the process) will set the KPIs of the MAAR chart and show them in the dashboard. As the reader can notice, in figure 3 , the mask developed allows supervising all the stages of the continuous improvement cycle.

\section{Step 1 - Monitor}

In this step, the dashboard shows the performance supervised by the KPIs defined. The graph shows the last six periods (this can be modified by the analyst) that are necessary for comparing the same indicator in previous periods.
If the MAAR-chart methodology is implemented on informatics system, it is possible in real time to choose the period analysis and have a value and trend of KPI; for example, if the analyst chooses one day as a period, then the trend showed is related to one week; if the period selected is one month the trend showed is related to one semester, e.g.

Moreover, it is possible to show more parameters significant for the process analyzed (Figure 4 shows an example of the graphs). This graph allows highlighting the KPI trend with the related parameters.

The information of the graphs is obtained by the enterprise database and it shows the trend of each parameter that concurs to obtain the total KPI value.

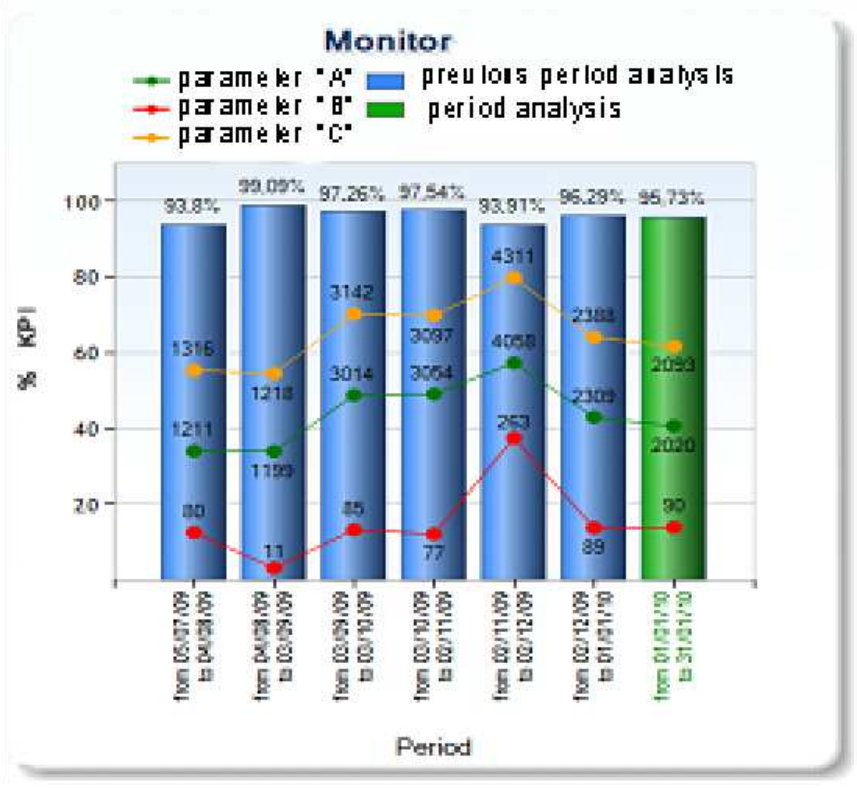

Fig 4. Example of Performance Graph 


\section{Step 2 - Analysis}

In this step, the dashboard highlights the parameters that affect negatively the KPI analyzed, and in particular on the KPI defined in the objective to pursue. Several parameters can be summarized within the same graphs that allow a rapid analysis of the trend. These parameters are organized as a
Pareto diagram (e.g. choose the parameter which has the highest impact on the costs of not quality).

Figure 5 shows the example of Pareto; the analyst can easily observe the contribution of each parameter. Then, the analyst can investigate the more relevant parameters for the improvement analysis.

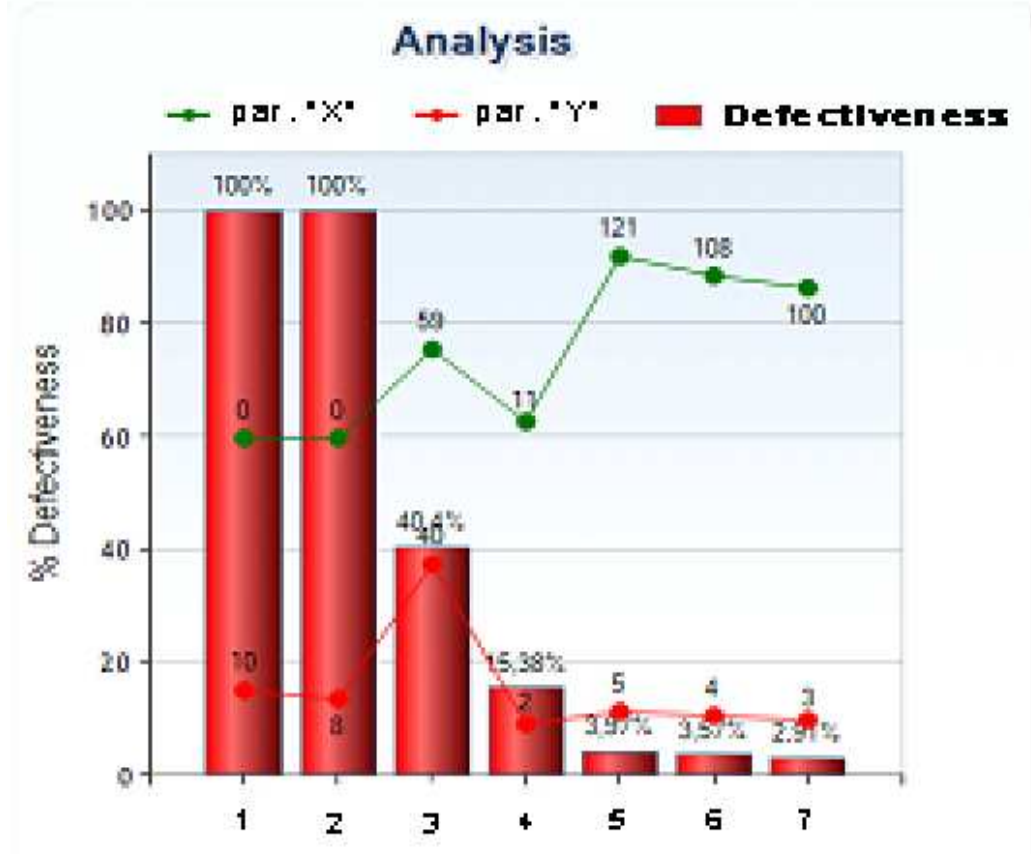

CONTRI B UTOR

Fig 5. Example of Pareto Diagram

\section{Step 3-Action}

In this step, the analyst can introduce the corrective actions and supervise the progress of them. The introduction of new actions is performed by the procedure described in the following. The analyst has to activate the "action" panel. The minimal requirements to introduce a new action are the following (see figure 6):

1. Part Number: this part number is a parameter which has a negative effect on the KPI. The part number is related to the parameters shown in the monitoring step. In fact, each part number is the parameter that 
has a negative effect on the performance analyzed.

2. Attachment: in this area, all the files necessary are attached for mapping the corrective action (in this area e.g. vi is the document that reduce the meeting of quality review or document received by external partner;...). This allows managing to manage all the information related to the actions introduced.

3. Prog.: it is a progressive identification of the corrective action;

4. Progress: it is the percentage progress of the corrective action. It allows monitoring the state of the corrective action.

5. Vendor: in this area, the provenance of the part number is indicated; this area is used if the action involves external actor from ANSALDO.
6. Action: in this part, a shortly description of corrective action is indicated;

7. date input: this part indicates the starting date of corrective action and this date is inserted automatically into the system;

8. delivery date: this part indicates the closing date of corrective action;

9. date: this part indicates the starting date of corrective action;

10. Internal Action Responsible: it is the internal action responsible for the corrective action;

11. External Action Responsible: it is the external action responsible for the corrective action.

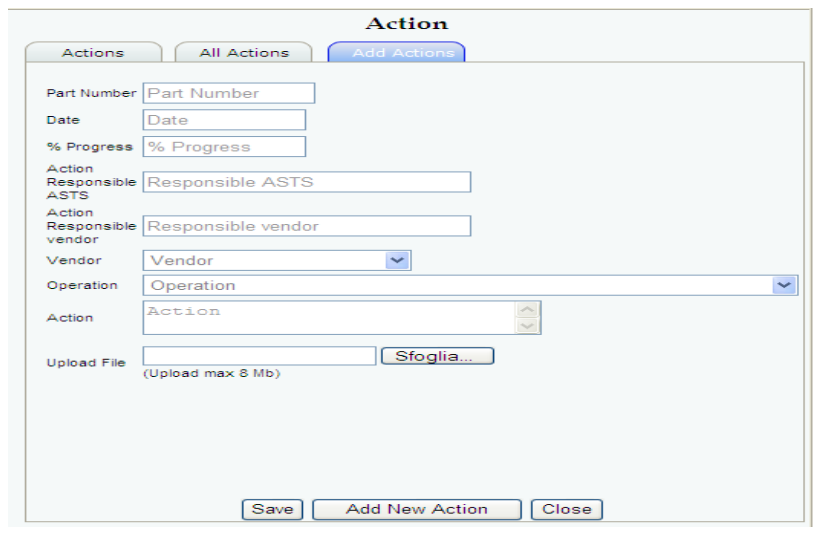

Fig 6. Screen for Corrective Action Opened and Update

Figure 7 shows the mask of the action section. It's always possible in the action section to show:

1) under windows "action", when effectuated by the dynamic selection, it's possible to only show corrective actions correlated with the selection;
2) under windows "all action" it is possible to show all actions inserted in the system.

For all views, it is possible to dedicate for each parameter and possible selection, sorted for each parameter and possible selection, corrective action for updating the percentage of progress or attach other material on this argument (see figure 7). 


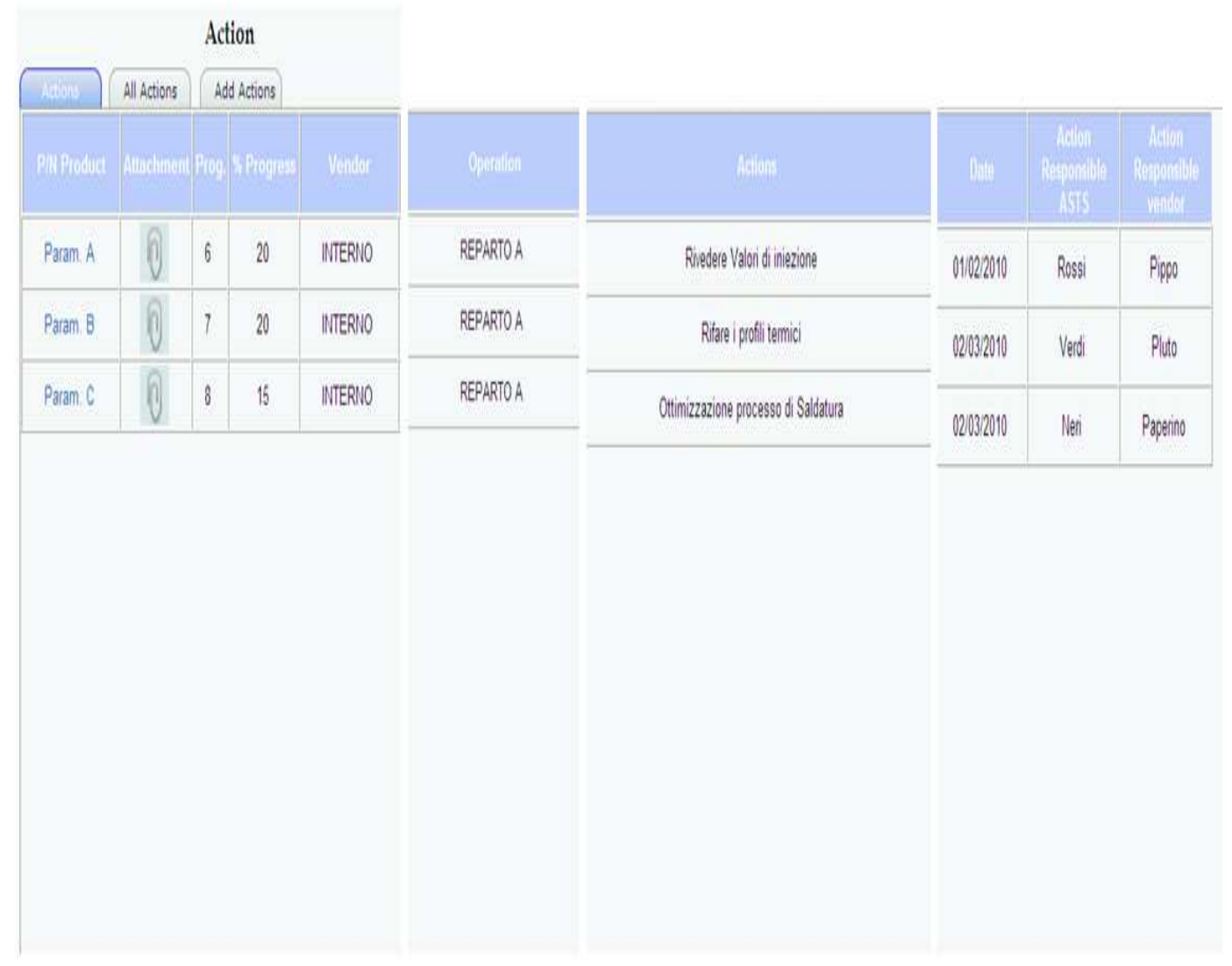

Fig 7. Screen for Corrective Action Show

\section{Step 4 - Review}

In this step (see figure 8), the parameters that have a negative effect on the KPI are compared before and after the corrective actions are introduced in the previous step.
In this section, the progress of each contributor, who has a negative impact on KPI (set by the system), can be monitored on the last six periods. 

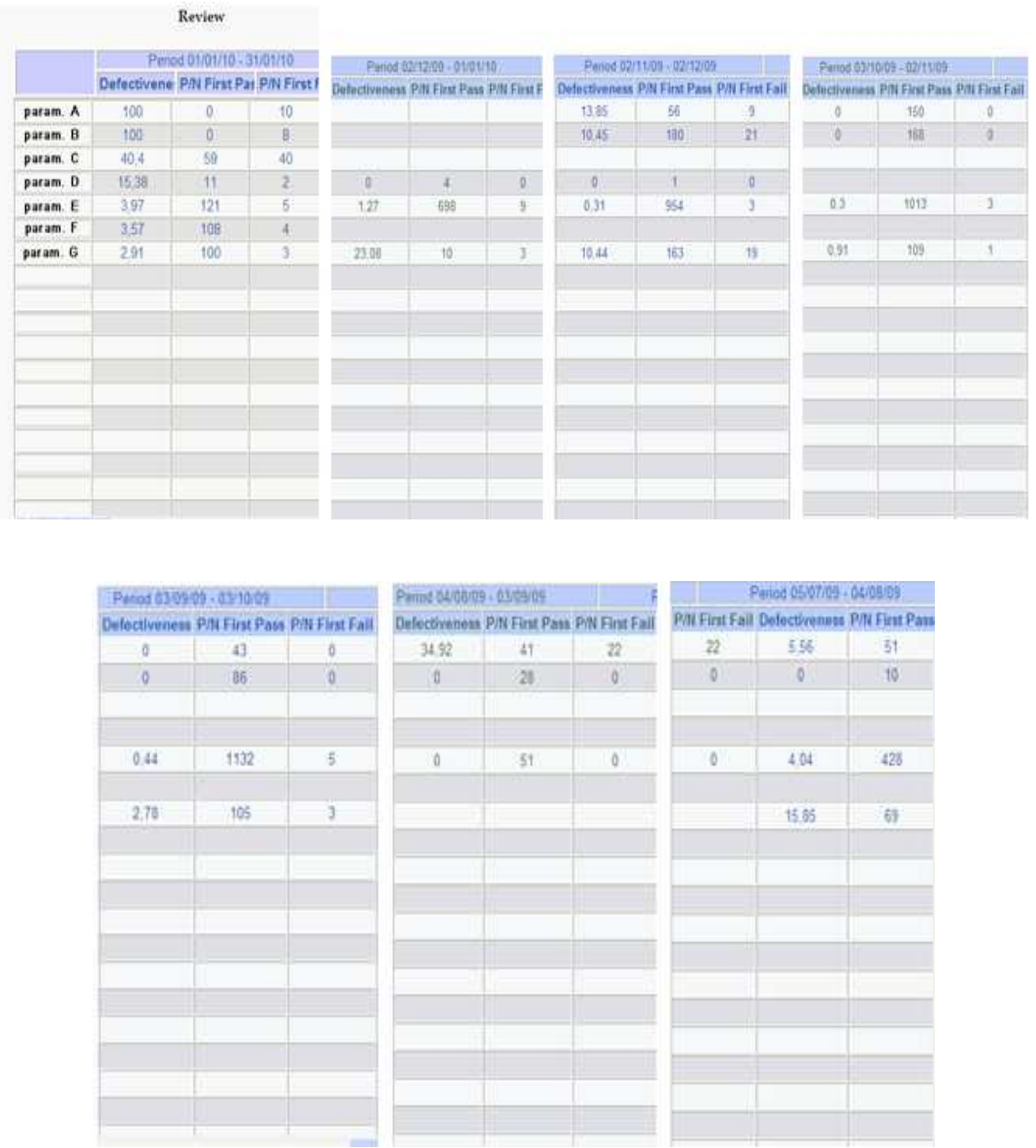

Fig8. Screen For Monitor the Progress

As shown in figure 3, this methodology can monitor directly and in real time the KPIs and if there is a need for a lower level of analysis, it is possible to use the same methodology to monitor the main KPI.

We will have a dashboard with KPI and the parameter $A$ we will have:

Section monitor for the parameter $A$;
The section of the Pareto Analysis of the contributors has a negative effect on the parameter $A$;

Section review to monitor the progress of all the negative contributors to the parameter A;

$>$ The Action section devoted only to remedial actions parameter $A$.

So we will have the same parameters but with relatively dashboard KPI major accidents. 
It is possible and necessary to lower the level of analysis to reach a level that can control the main KPI.

\section{Discussion of Case Study}

This methodology has been studied experimented, designed and implemented in a production environment. The methodology has been studied in Ansaldo STS Italy of Tito and was first implemented on electronics and certification of electronics boards, and later extended to the whole factory to monitor and control the entire production of all products. After two years of its implementation, the following considerations can be reached:

1) The tool has proved to be efficient and effective for monitoring and controlling production quality.

2) It has further helped improve the already high levels of quality products that distinguish Ansaldo STS
3) Its implementation also monitor launches of new production has proven to be an effective and efficient way to improve performance and product quality since the first launch of new products.

4) It has also proven to be flexible, effective and efficient in the short term and has allowed structuring a system of continuous improvement.

5) The methodology presented itself as an effective, efficient and dynamic indicator to monitor any process or system.

In year 2009, for example, only in Tito plant 529 different electronic boards code were managed; the quantity for each code was from some units to about 6.000 pieces per type.

In the first part of the MAAR Chart study and implementation, six productive departments were chosen (in all production area) (see figure 9).

\begin{tabular}{|c|c|c|c|c|}
\hline id & codice & descrizone & codhtcoto_sep & is scheda \\
\hline 1 & 0104 & Reparto SCHEDESWD & True & True \\
\hline 2 & 0204 & Reparto SCHEDEPTH & True & True \\
\hline 3 & 0224 & Reparto SCHEDE:CT & True & True \\
\hline 4 & 0234 & Reparto COLLALDOFINZZONALESCHEDE & True & True \\
\hline 5 & 0304 & Reparto VEN VCLATURA SCHEDE & True & True \\
\hline 10 & 0002 & Reparto BURN IN SCHEDE & False & True \\
\hline
\end{tabular}

Fig 9. Productive Departments

Each department standardizes (as much as possible) the possible defect that can be chosen in each department (see figure 10). 


\begin{tabular}{|c|c|c|c|}
\hline id & codice & descrizione & operazione_id \\
\hline 1 & $\sec$ & corto circuito & 2 \\
\hline 2 & sfr & sald fredde & 2 \\
\hline 3 & $\operatorname{sgr}$ & grasse & 2 \\
\hline 4 & SST & senza risalita & 2 \\
\hline 5 & sto & forate & 2 \\
\hline 6 & sma & pin non saldato & 2 \\
\hline 7 & and & compo soll - assemb| & 2 \\
\hline 8 & cch & handling rotto & 2 \\
\hline 9 & $\mathrm{cma}$ & comp manc & 2 \\
\hline 10 & mic & microsfere & 2 \\
\hline 11 & $\operatorname{scc}$ & saldature in presenza di cortocircuito & 3 \\
\hline 12 & sme & saldature con menisco non standard & 3 \\
\hline 13 & sma & saldature mancanti & 3 \\
\hline 14 & sfr & saldature fredde & 3 \\
\hline 15 & SST & saldature senza risalita o componenti non saldati & 3 \\
\hline
\end{tabular}

Fig 10. Defects

The following is the first test of the methodology that was decided to be extended throughout the factory. The Important steps are the implementation of key performance indicators and the selection of monitoring points. The key performance indicators used in the case study developed are the following.

Quality Boards:

Yield of electronic Board: $\frac{\text { Number of electronic boards comply }}{\text { Total Number of electronic boards }} \times 100$

Expression (1) computes the percentage of electronic boards that comply with the specifications related to the total number of electronic boards manufactured by the process analyzed.
Quality single Boards:

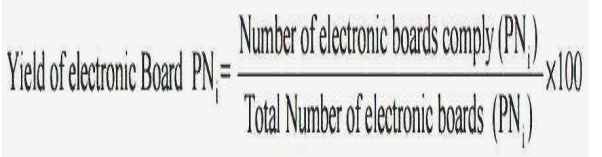

Expression (2) evaluates the percentage of electronic boards that comply with the specifications related to the total number of electronic boards for each part number $i$-th (PNi).

After an initial period of experimentation, the Methodology was introduced for monitoring other KPI (also in an economical field), for example other types of indicators are as follows: 


\begin{tabular}{|l|l|}
\hline Raw materials stock coverage: & $\begin{array}{l}\text { Stock value at a certain moment on the average value of the } \\
\text { output for next 3 months (budget or forecast). }\end{array}$ \\
\hline WIP stock coverage: & $\begin{array}{l}\text { WIP stock value at a certain moment on the average value } \\
\text { of the output for next 3 months (budget or forecast). }\end{array}$ \\
\hline Variance on WO: & $\begin{array}{l}\text { Variance is the difference between goods released in stock } \\
\text { at standard cost and actual costs on WO (material + labor) } \\
\text { It can be positive or not. }\end{array}$ \\
\hline WO efficiency: & $\begin{array}{l}\text { Ratio of hours spent on WO on the period on the number of } \\
\text { hours expected in the routings. }\end{array}$ \\
\hline Unplanned materials & $\begin{array}{l}\text { Ratio of the amount of raw materials used in addition to the } \\
\text { BOM on the total amount of components consumed for the } \\
\text { WO on the period }\end{array}$ \\
\hline
\end{tabular}

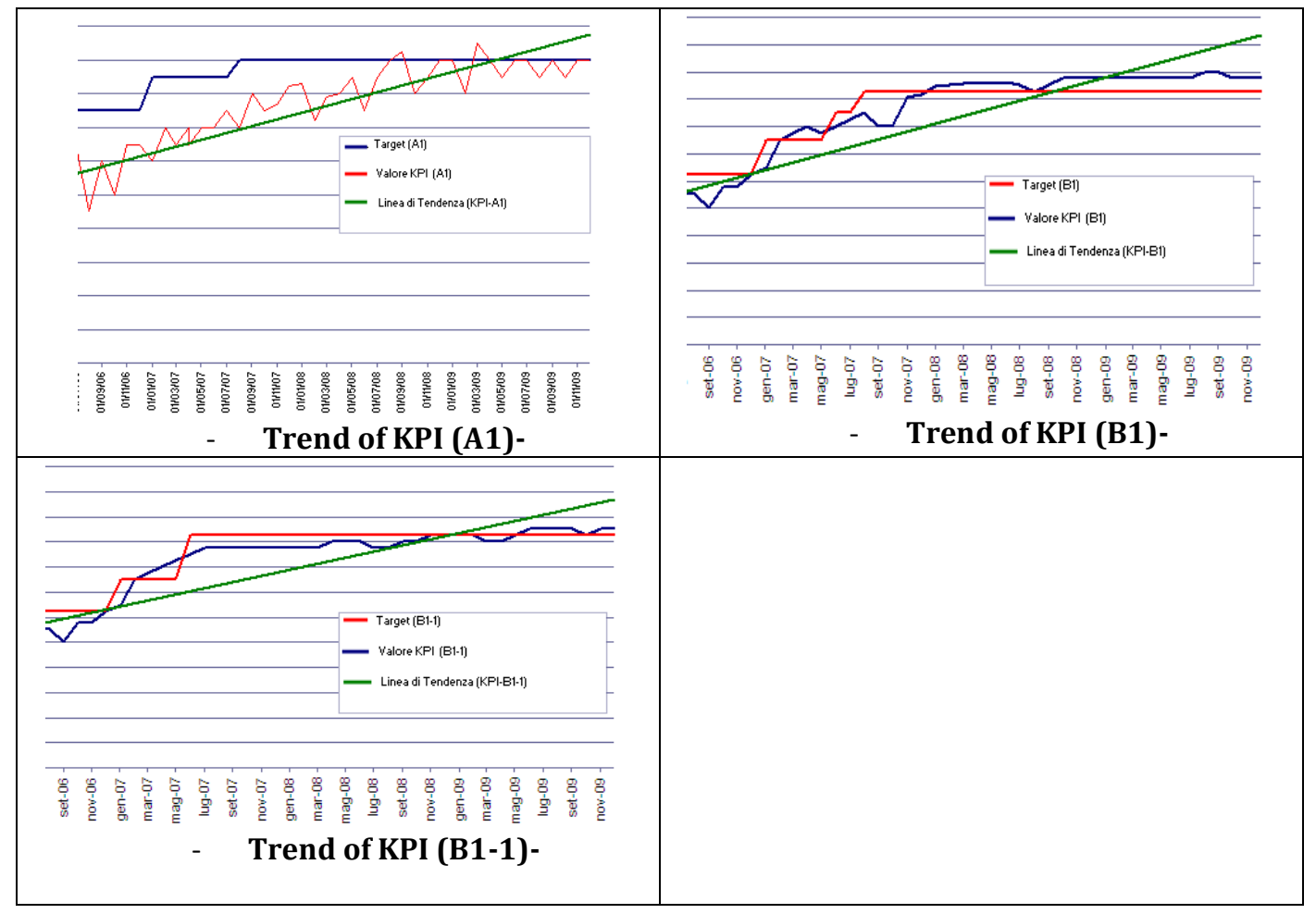

Fig 11. Performance Improvements 
The improvements of the performance obtained by the proposed approach are shown in the figure 11.

Figure 11 shows the trend of three KPIs monitored from September 2006 to November 2009. The red line is the target of the indicator observed, while the blue line is the real value of the KPIs. As the reader can notice, the introduction of the proposed methodology allowed improving significantly all the three KPIs analyzed. The green line shows the trend of the KPI over the periods observed. The improvement of the KPIs allows reaching to reach the target objective of the KPIs.

\section{Conclusions and Future Development}

The study presented in this paper focuses on the implementation and deployment of a methodology for continuous performance improvements defined MAAR charts at ANSALDO STS S.p.A., Italy area Manufacturing. The MAAR charts approach is based on the integration of the continuous improvement process throughout the following steps: Monitor, Analysis, Action and Review.

We can confirm that this project provides the firm with a lot of advantages such as:

1) monitoring any indicator in operative, structured and in real time mode;

2) monitor each contributor that adversely affect on the main indicator;

3) using the same methodology for several levels of analysis in order to obtain a totally control of KPIs;

4) Monitoring over time the trend of indicators.

5) Monitoring over time the trends of each negative contributor on the indicator.

6) Corrective action system to map and assess the temporal effects.
7) Having in a single compact panel all information for monitoring and implementing corrective actions of any indicator.

ANSALDO STS took advantage of the flexibility and scalability of the proposed approach in order to make decisions and focus on essential needs while maintaining full adaptability to develop the system and respond to changing requirements. In addition, this integration of data between the different functions allows easy analysis of performance indicators, which in the past used to be an extremely time-consuming process. As planned, ANSALDO STS will continue to extend the use of MAAR charts approach to its other processes of the manufacturing. In parallel, it will make enhancements and will introduce further developments to further maximize the benefits. This ultimate goal will allow the firm to have a complete overview of all its internal and external processes with users, partners, suppliers, and customers, on one single platform.

Future development paths concern: the possibility to extend the methodology described in different enterprise areas in order to investigate the robustness of the methodology for several applications; the development of a decision support tool to propose the corrective actions to the analyst.

\section{References}

Al-Ahmari, A. M. A. \& Ridgway, K. (1999). "An Integrated Modeling Method to Support Manufacturing Systems Analysis and Design," Computers in Industry, 38, 225-238.

Bravoco, R. and Yadav, S. (1985), 'A methodology to model functional structure of an organization', Computers in Industry, 6, 345-361.

Carrie, A. \& Macintosh, R. (1997). "An Assessment of GRAI Grids and their Use in the Strathclyde Integration Method," Production Planning and Control, 8,106-113. 
Doumeingts, G. (1985). "How to Decentralize Decision through GRAI Model in Production Management," Computers in Industry, 6, 501514.

Doumeingts, G., Vallespir, B. \& Chen, D. (1995). "Methodologies for Designing CIM System: a Survey," Computers in Industry, 25, 263-280.

Down, E., Clare, P. \& Coe, T. (1988). 'Structured System Analysis and Design Method,' New York: Prentice-Hall.

Eva, M. (1992). 'SSADM Version 4 - A User Guide,' London, McGraw-Hill.

Friday-Stroud S. S. \& Sutterfield J. S. (2007). "A Conceptual Framework for Integrating Sixsigma and Strategic Management Methodologies to Quantify Decision Making," the TQM Magazine, 19(6), 561-571.

Grislain, J. \& Pun, L. (1979). 'Graphical Methods for Production Control,' Fifth International Conference on Production Research, Amsterdam 12-16 August 1979, 265-270.

Huang, S. H., Dismukes, J. P., Shi, J., Su, Q., Wang, G., Razzak, M. A. \& Robinson, D. E. (2002). "Manufacturing System Modeling for Productivity Improvement," Journal of Manufacturing Systems, 21 (4), 249-259.

Marca, D. A. \& McGowan, C. L. (1987). Structured Analysis and Design Technique, New York: McGraw Hill.

Muthiah K. M. N. \& Huang S. H. (2006). "A Review of Literature on Manufacturing Systems Productivity Measurement and Improvement," International Journal of Industrial and Systems Engineering, 1(4), 461484.

Pandya, K. (1995). 'Review of Modeling Techniques and Tools for Decision Making in Manufacturing Management,' IEE Proceedings on Science, Management and Technology, 142 (5), 371-377.

Ross, D. T. \& Schoman, K. (1977). "Structured Analysis for Requirement Definition," IEEE Transactions on Software Engineering, SE, 3, 6-15.

Ross, D. T. (1985). 'Application of SADT,' IEEE Transactions on Computers, April, 25-34.

Santarek, K. \& Buseif, I. M. (1998). "Modeling and Design of Flexible Manufacturing Systems Using SADT and Petri Net Tools," Journal of Materials Processing Technology, 76, 212218.

Taninecz, G. (2004a). 'Faster but not Better,' Industry Week, May.

Taninecz, G. (2004b). 'Long-term Commitments,' Industry Week, February.

Wazed, M. A. \& Ahmed, S., (2009). "Theory Driven Real Time Empirical Investigation on Joint Implementation of PDCA and 5S for Performance Improvement in Plastic Moulding Industry," Australian Journal of Basic and Applied Sciences, 3(4), 3825-3835.

Witcher, B. J. \& Chau, V. S. (2007). "Balanced Scorecard and Hoshinkanri: Dynamic Capabilities for Managing Strategic Fit," Management Decision, 45(3), 518-538.

Witcher, B. J. \& Chau, V. S. (2008). "Contrasting Uses of Balanced Scorecards: Case Studies at Two UK Companies," Strategic Change, 17, 101-114. 